\title{
Study on reduction of hand-transmitted vibration in self propelled vertical conveyor reaper by isolators
}

\author{
T.R. Gururaj and A.K. Mehta
}

Received : 12.07.2020; Revised : 15.08.2020; Accepted : 15.09.2020

See end of the Paper for authors' affiliation

Correspondence to :

T.R. Gururaj

GPS Institute of Agricultural

Management, Bengaluru

(Karnataka) India

Email: gururajsuni@gmail.com
- ABSTRACT : The self propelled vertical conveyor reaper is commonly used for harvesting wheat, rice etc. It has become a main or the sole of mechanical power source on small and medium size farms in India. The operators of VCR are exposed to a high level of vibration arising from single cylinder engine during field operations. The vibration from the VCR is transmitted from handle to hands, arms and shoulders. In the present study, experiments were conducted to reduce the vibration extent in VCR for two operational conditions i.e. transportation on bitumen road and wheat harvesting operation by using isolators in between engine and chassis. The vibrations were measured at engine speed 2200 and $2800 \mathrm{rpm}$. In this study it was found that the vibration magnitudes decreased with increase in engine speed from 2200 to $2800 \mathrm{rpm}$ in both operational conditions. The highest vibration values were observed in $\mathrm{x}$-direction. The maximum frequency-weighted vibration acceleration (rms) in $\mathrm{x}$-direction was 18.76 and $22.8 \mathrm{~ms}^{-2}$ in transportation and wheat harvesting, respectively. After incorporation of isolators the vibration total values reduced at $2200 \mathrm{rpm}$ form $22.8 \mathrm{~ms}^{-2}$ to $9.63 \mathrm{~ms}^{-2}$ and $28.11 \mathrm{~ms}^{-2}$ to $12.57 \mathrm{~ms}^{-2}$ in transportation and wheat harvesting, respectively (Fig. 1 and 2). Whereas at $2800 \mathrm{rpm}$ the vibration total values reduced form $12.93 \mathrm{~ms}^{-2}$ to $5.85 \mathrm{~ms}^{-2}$ and $17.86 \mathrm{~ms}^{-2}$ to $8.42 \mathrm{~ms}^{-2}$, respectively. The average increment in 8 hour exposure time for occurrence of white finger syndrome from 1.16 to 2.88 year and 0.93 to 2.17 year for isolators in transportation and wheat harvesting, respectively

- KEY WORDS : VCR, Engine speed, Wheat harvesting, Vibrations, Isolators, White finger syndrome

- HOW TO CITE THIS PAPER : Gururaj, T.R. and Mehta, A.K. (2020). Study on reduction of hand-transmitted vibration in self propelled vertical conveyor reaper by isolators. Internat. J. Agric. Engg., 13(2) : 212-219, DOI: 10.15740/HAS/IJAE/13.2/212-219. Copyright@2020: Hind Agri-Horticultural Society. 